\title{
SPATIAL TRAFFIC NOISE POLLUTION ASSESSMENT - A CASE STUDY
}

\section{MOHAMMAD REZA MONAZZAMํㅜ, ELHAM KARIMI², MAJID ABBASPOUR ${ }^{3}$, PARVIN NASSIRI $^{4}$, and LOBAT TAGHAVI}

\author{
${ }^{1}$ Tehran University of Medical Sciences, Tehran, Iran \\ Department of Occupational Hygiene, School of Public Health and Center for Air Pollution Research (CAPR), \\ Institute for Environmental Research (IER) \\ ${ }^{2}$ Islamic Azad University, Tehran, Iran \\ Department of Environmental Science, Faculty of Environment and Energy, Science and Research Branch \\ ${ }^{3}$ Sharif University of Technology, Tehran, Iran \\ School of Mechanical Engineering \\ ${ }^{4}$ Tehran University of Medical Sciences, Tehran, Iran \\ Department of Occupational Health School of Public Health
}

\begin{abstract}
Objectives: Spatial assessment of traffic noise pollution intensity will provide urban planners with approximate estimation of citizens exposure to impermissible sound levels. They could identify critical noise pollution areas wherein noise barriers should be embedded. The present study aims at using the Geographic Information System (GIS) to assess spatial changes in traffic noise pollution in Tehran, the capital of Iran, and the largest city in the Middle East. Material and Methods: For this purpose, while measuring equivalent sound levels at different time periods of a day and different days of a week in District 14 of Tehran, wherein there are highways and busy streets, the geographic coordination of the measurement points was recorded at the stations. The obtained results indicated that the equivalent sound level did not show a statistically significant difference between weekdays, and morning, afternoon and evening hours as well as time intervals of $10 \mathrm{~min}, 15 \mathrm{~min}$ and $30 \mathrm{~min}$. Then, 91 stations were selected in the target area and equivalent sound level was measured for each station on 3 occasions of the morning (7:00-9:00 a.m.), afternoon (12.00-3:00 p.m.) and evening (5:00-8:00 p.m.) on Saturdays to Wednesdays. Results: As the results suggest, the maximum equivalent sound level $\left(\mathrm{L}_{\mathrm{eg}}\right)$ was reported from Basij Highway, which is a very important connecting thoroughfare in the district, and was equal to $84.2 \mathrm{~dB}(\mathrm{~A})$, while the minimum equivalent sound level $\left(\mathrm{L}_{\mathrm{eq}}\right)$, measured in the Fajr Hospital, was equal to $59.9 \mathrm{~dB}(\mathrm{~A})$. Conclusions: The average equivalent sound level was higher than the national standard limit at all stations. The use of sound walls in Highways Basij and Mahallati as well as widening the Streets 17th Shahrivar, Pirouzi and Khavaran, benchmarked on a map, were recommended as the most effective mitigation measures. Additionally, the research findings confirm the outstanding applicability of the Geographic Information System in handling noise pollution data towards depicting noise pollution intensity caused by traffic.
\end{abstract}

Key words:

Noise pollution, Equivalent sound level, Noise sensitive centers, GIS, Traffic-induce noise, Vehicle traffic

Received: November 5, 2013. Accepted: October 22, 2014.

Corresponding author: E. Karimi, Islamic Azad University, Department of Environmental Science, Faculty of Environment and Energy, Science and Research Branch, 7 Tir Square, 299 Shariati Alley, Second Floor, Unit 4, 1574743187 Tehran, Iran (e-mail: Elham_karimi63@yahoo.com). 


\section{INTRODUCTION}

Urban transportation development is essential in increasing efficiency of moving people and goods within metropolitan cities. However, simultaneously its consequent environmental impact must be evaluated and mitigated, as possible. Accordingly, noise spatial modeling would be quite an applicable tool for spatial quantification of noise traffic intensity in susceptible areas [1]. Noise caused by vehicles is a major source of dissatisfaction with the environment in residential areas, which can cause severe health problems [2].

Noise pollution health risks do not emerge rapidly, but one should not fail to notice that during the recent century, many large cities have been facing this problem and its consequences as an intricate environmental concern [3-7]. Therefore, during the recent years there has been an increasing interest in application of the Geographic Information System (GIS) in noise pollution studies. However, their number is still limited. Reed et al. (2012) introduced a GIS tool, SPreAD-GIS, for modeling anthropogenic noise propagation in natural ecosystems by means of which it would be possible to incorporate commonly available datasets on land cover, topography, and weather conditions, and to calculate noise propagation patterns and excess noise above ambient conditions for $1 / 3$ octave frequency bands around 1 or multiple sound sources [8]. Ko et al. (2011) suggested a scheme to develop a roadtraffic noise map for the city of Chungju, Republic of Korea using GIS to assess noise pollution of the city [9].

Hence, noise pollution control is a major issue that draws many urban planners' attention. Noise can cause nerve irritation, raise heart beat rate and blood pressure, and leave undesirable effects on body organs [10-14]. Noise pollution at high sound pressure levels (over $85 \mathrm{~dB}$ ) can directly affect the organ of hearing through temporary hearing threshold shift and, in the case of long term exposure, permanent hearing threshold shift. At a lower equivalent-continuous A-weighted sound pressure level, in a range between $50 \mathrm{~dB}$ and $80 \mathrm{~dB}$, would result in annoyance, disturbance, inconvenience and impaired comfort. In other words, some part of noise effects is associated with its impact on the nervous system and mental and behavioral status [15-17].

Li et al. (2002) developed a road traffic noise prediction model based on local environmental standards, vehicle types and conditions of traffic [18]. In 2009 Pamanikabud and Tansatcha predicted and displayed the impact of motorway traffic noise on nearby buildings by utilizing a motorway traffic-noise model combined with a geoinformatics technique [19]. Noise mapping research was conducted in the Pusan National University of Korea using the Global Positioning System (GPS) data. The results have shown a high noise exposure of over $65 \mathrm{~dB}(\mathrm{~A})$ mainly near the roads and newly developed areas, wherein the reflective effects of the buildings have been apparent [20]. In a noise mapping in Taiwan, the analysis results have shown maximum and minimum sound levels of $69.6 \mathrm{~dB}(\mathrm{~A})$ and $59.3 \mathrm{~dB}(\mathrm{~A})$ during summer mornings and winter nights, respectively. In addition, the results have revealed that $90 \%$ of the total population of the Taiwan City is exposed to unallowable sound pressure levels [21].

A research has been done on the temporal-spatial pattern of traffic noise pollution in Karachi, Pakistan. The results have revealed that higher sound pressure levels usually occur in the mornings and evenings as a result of behavioral pattern of Karachi residents. The average sound level exceeds $66 \mathrm{~dB}(\mathrm{~A})$, which, according to the World Health Organization (WHO) outdoor noise guidelines, can be really annoying, while peak level was over $101 \mathrm{~dB}(\mathrm{~A})$ and near $110 \mathrm{~dB}(\mathrm{~A})$ this can possibly result in hearing impairment [22].

In 2007 Tang and Wang conducted a research on the impact of urban fabric on traffic-induced noise and air pollution using the Calculation of Road Traffic Noise (CRTN) and the Operational Street Pollution Model (OSPM) models [23]. They have finally concluded that urban fabric in historical areas with narrower roads, complex road networks and a higher density of intersections lead to 
lower traffic volumes and thus, lower noise pollution. Ko et al. (2010) suggested a scheme to develop a noise map using GIS. They have finally managed to generate a 3-dimensional facade noise map to calculate the number of people exposed to a certain noise level [6].

In 2010 Fung and Lee identified a common parameter for assessing the impact of traffic-induced noise and air pollution on residential premises in Hong Kong [24]. They conducted a series of noise level and $\mathrm{PM}_{10}$ concentration measurements at roadsides of 2 busy roads in Hong Kong and in 10 case studies, residential units located nearby. They found that both the traffic-induced noise and the $\mathrm{PM}_{10}$ concentrations in the case of the study units exhibit a linear correlation with the logarithm of their corresponding distance from the road ( $\log \mathrm{R})$. Therefore, they concluded that $\log \mathrm{R}$ could be adopted as a common parameter for evaluating the combined impact of road traffic on the noise and air pollution of a residential unit.

The present study was conducted to assess traffic noise pollution of District 14 in Tehran Metropolitan City. Proximity of residential areas to the crowded streets and highways in the district reveals the importance of this research. It mainly aims at identification and measurement of noise pollution sources, noise pollution mapping using Arc GIS, comparison of noise pollution level at different land uses and comparison of the average sound pressure levels in the case of the main streets, passages, squares and junctions of the study area.

So far, numerous research has been done in the field of noise pollution assessment involving high volume of sampling during the study period, which was very time-consuming and costly. This project seeks to reduce the cost and study period by increasing the number of samples from the target area. For this purpose, a pilot study is supposed to be performed to compare the equivalent sound level $\left(\mathrm{L}_{\mathrm{eq}}\right)$ of different working days at different times of a day within the intervals of $10 \mathrm{~min}, 15 \mathrm{~min}$ and $30 \mathrm{~min}$. The present study detects the impact of urban fabric on the increased noise level in metropolitan cities.

\section{MATERIAL AND METHODS}

\section{The study area}

District 14 is one of the most crowded areas of Tehran. The district has an area of $23.64 \mathrm{~km}^{2}$ comprising $3.2 \%$ of the city area. According to 2006 Census, the district has a total population of 445138 people. As a very important connecting thoroughfare in the district the Basij Highway has provided rapid access to Tehran's highway network. Traffic of heavy vehicles in the high way increases noise pollution level in this area. Also as Piroozi and 17 Sharivar Streets are not wide enough and they are often too jampacked, never ending honks have been further deteriorating the noise pollution.

\section{The research methodology}

The present study was conducted in 2 phases - the main and pilot one. The procedure of the research at each phase is described below.

\section{The pilot phase}

The pilot phase was performed in order to determine changes in the equivalent sound pressure level within the weekdays and during different occasions of the morning, noon, and evening. For the pilot phase 6 stations were randomly selected in the district in a way that took into consideration all types of land use, i.e., residential, recreational, educational, commercial and residentialcommercial. Considering that the measurements were taken at 3 time-intervals of $10 \mathrm{~min}, 15 \mathrm{~min}$ and $30 \mathrm{~min}$ during the morning, noon and evening, 54 samples were taken within the working days (Saturdays, Mondays and Wednesdays) and 18 samples at the weekends. The study area also included noise sensitive areas, such as: hospitals and healthcare centers, and also different types of passages including highways, main streets, secondary passages and junctions (Figure 1).

While recording geographic coordinate of the measurement points using GPS (model: VISTA Garmin HCX), 


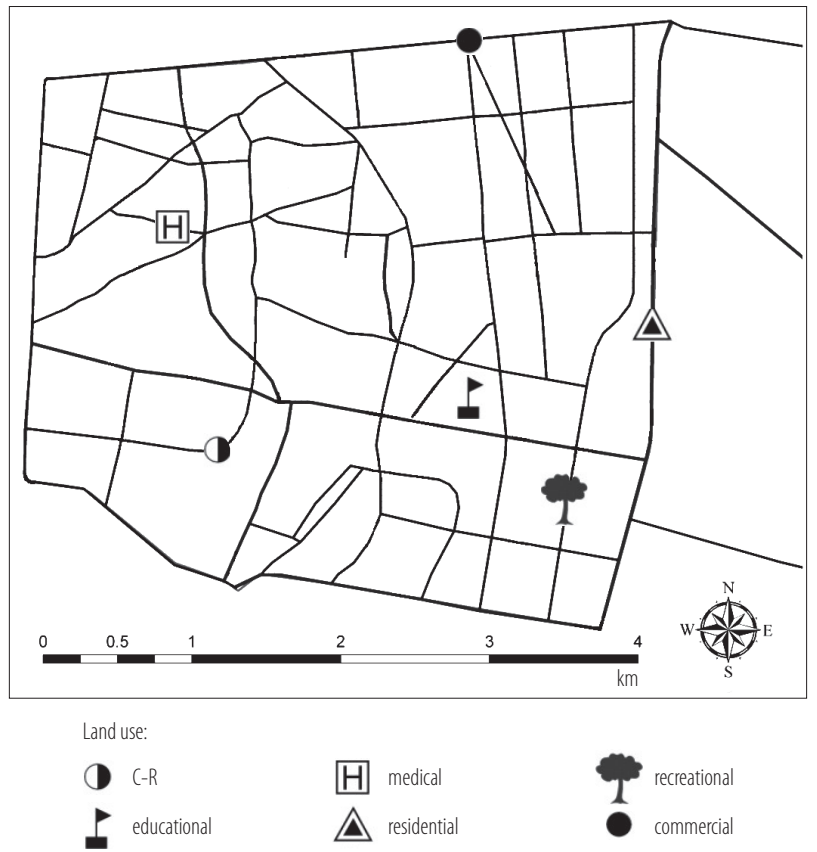

$\mathrm{C}-\mathrm{R}$ - commercial and residential land use.

Fig. 1. Dispersion of the stations in a pilot phase

the equivalent-continuous A-weighted sound pressure level was measured using a sound pressure level meter of B\&K2230 type.

The calibrated device was mounted on the base at a distance of 3 meters from the edge of the roadway at a height of $130 \mathrm{~cm}$ from the ground. Afterwards, measurements were taken at each station on Saturdays, Mondays, Wednesdays and Fridays (holiday) at 3 occasions in the morning (7:00-9:00 a.m.), noon (1:00-3:00 p.m.) and evening (5:00-8:00 p.m.) by which the $\mathrm{L}_{\text {Aeq }}$ was recorded at $10 \mathrm{~min}, 15 \mathrm{~min}$ and $30 \mathrm{~min}$ intervals. The results were then analyzed using SPSS16.0 software.

\section{Main phase}

During this phase, it was estimated that a total number of 91 samples should be taken into account in order to reach the confidence level of $95 \%$. Therefore, $\mathrm{L}_{\text {Aeq }}$ was taken at 91 stations. Setting the sound level meter on

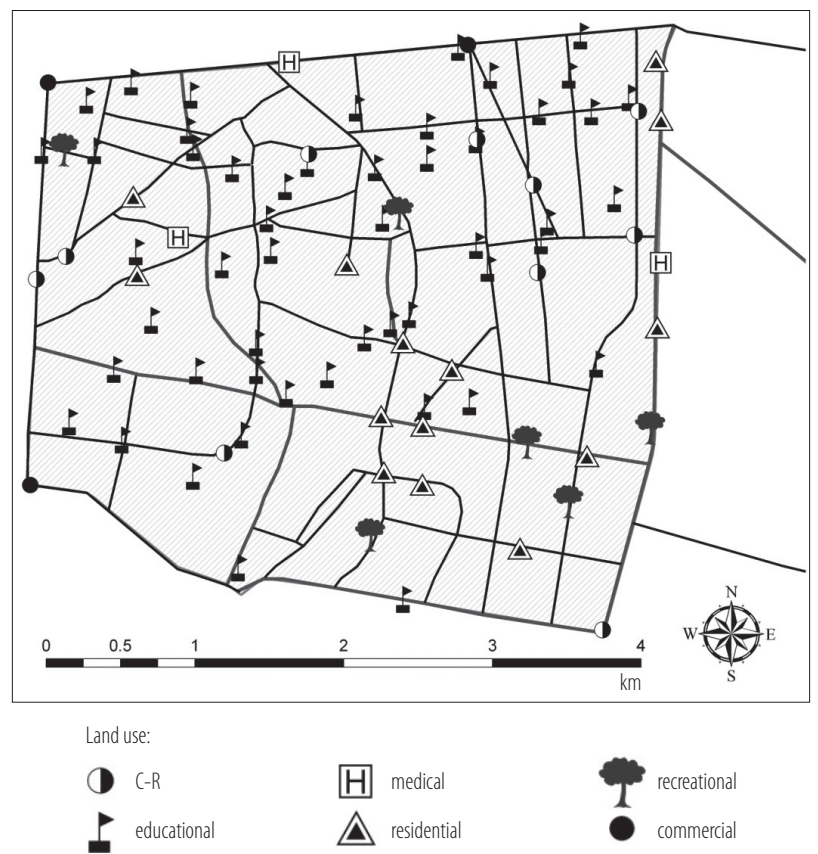

$\mathrm{C}-\mathrm{R}$ - commercial and residential land use.

Fig. 2. Distribution of the measurement stations at different land uses of the study area

a fast mode, the $\mathrm{L}_{\text {Aeq }}$ was measured according to the Environment Protection Agency (EPA) criteria for road traffic noise [25]. A table was developed in MS-Excel containing descriptive information on the stations such as: name and code, coordination, daily $\mathrm{L}_{\text {Aeq10-min, }}$, land use and type of a street, which were then used in Arc GIS for spatial analyses. Figure 2 shows location of all the measurement stations in District 14. Symbols in the figure represent measurement stations.

\section{RESULTS AND DISCUSSION}

\section{The pilot phase}

The measurement results of the equivalent-continuous A-weighted sound pressure level at different time intervals during the weekdays are presented in Table 1.

In the pilot stage, in order to compare workings days and holidays, the normal distribution of data was initially examined by the use of a non-parametric test. 
Table 1. The equivalent-continuous A-weighted sound pressure level $\left(\mathrm{L}_{\text {Aeq }}\right)$ at different time intervals during the weekdays and weekend

\begin{tabular}{|c|c|c|c|c|c|c|c|c|c|c|}
\hline \multirow{3}{*}{ Station No. } & \multirow{3}{*}{$\begin{array}{c}\text { Occasion } \\
\text { (time interval) }\end{array}$} & \multicolumn{9}{|c|}{$\begin{array}{c}\mathrm{L}_{\mathrm{Aeq}} \\
{[\mathrm{dB}(\mathrm{A})]}\end{array}$} \\
\hline & & \multicolumn{3}{|c|}{ morning } & \multicolumn{3}{|c|}{ afternoon } & \multicolumn{3}{|c|}{ evening } \\
\hline & & $10 \mathrm{~min}$ & $15 \mathrm{~min}$ & $30 \mathrm{~min}$ & $10 \mathrm{~min}$ & $15 \mathrm{~min}$ & $30 \mathrm{~min}$ & $10 \mathrm{~min}$ & $15 \mathrm{~min}$ & $30 \mathrm{~min}$ \\
\hline \multirow[t]{2}{*}{1} & weekdays & 82.3 & 82.1 & 82.0 & 82.0 & 81.8 & 81.6 & 81.9 & 81.8 & 82.2 \\
\hline & weekend & 80.3 & 80.7 & 80.9 & 81.8 & 81.4 & 80.8 & 80.2 & 80.1 & 79.9 \\
\hline \multirow[t]{2}{*}{2} & weekdays & 79.2 & 79.4 & 79.5 & 79.3 & 79.2 & 79.0 & 78.5 & 78.8 & 79.0 \\
\hline & weekend & 79.4 & 79.0 & 79.0 & 77.2 & 77.1 & 77.5 & 76.8 & 77.5 & 77.4 \\
\hline \multirow[t]{2}{*}{3} & weekdays & 63.1 & 63.0 & 62.9 & 63.9 & 63.1 & 63.6 & 63.8 & 63.8 & 63.8 \\
\hline & weekend & 60.1 & 60.8 & 60.9 & 61.4. & 61.6 & 61.8 & 60.2 & 60.8 & 60.9 \\
\hline \multirow[t]{2}{*}{4} & weekdays & 71.4 & 71.2 & 71.1 & 71.7 & 71.8 & 71.9 & 71.9 & 72.0 & 72.0 \\
\hline & weekend & 69.2 & 69.8 & 69.9 & 69.7 & 69.3 & 69.1 & 71.4 & 71.2 & 70.3 \\
\hline \multirow[t]{2}{*}{5} & weekdays & 70.5 & 70.3 & 70.1 & 70.1 & 70.0 & 69.8 & 70.2 & 70.2 & 70.1 \\
\hline & weekend & 66.0 & 66.1 & 67.5 & 66.5 & 66.5 & 67.5 & 65.8 & 67.2 & 69.4 \\
\hline \multirow[t]{2}{*}{6} & weekdays & 69.4 & 69.3 & 69.1 & 69.1 & 68.8 & 68.7 & 69.0 & 69.3 & 69.1 \\
\hline & weekend & 65.0 & 65.1 & 64.3 & 65.3 & 65.2 & 66.4 & 64.7 & 66.1 & 68.5 \\
\hline
\end{tabular}

The $\mathrm{L}_{\text {Aeq10 }}$ was equal to $72.62 \mathrm{~dB}$ for working days (standard deviation $(\mathrm{SD})=6.3$ ) and $70.05 \mathrm{~dB}$ for holidays ( $\mathrm{SD}=7.3$ ); the values for 15 and 30 min-intervals are presented in Table 2.
The t-test statistical analysis was used to compare the equivalent-continuous A-weighted sound pressure levels of working days and holidays within the timeintervals of $10 \mathrm{~min}, 15 \mathrm{~min}$ and $30 \mathrm{~min}$. The p-values of

Table 2. The equivalent-continuous A-weighted sound pressure level $\left(\mathrm{L}_{\text {Aeq }}\right)$ at the intervals of $10 \mathrm{~min}, 15 \mathrm{~min}$ and $30 \mathrm{~min}$ during the working days and holidays

\begin{tabular}{lcccc}
\hline \multirow{2}{*}{ Time interval } & $\begin{array}{c}\text { Measurement stations } \\
(\text { total })\end{array}$ & \multicolumn{2}{c}{$\begin{array}{c}\mathrm{L}_{\text {Aeq }} \\
{[\mathrm{dB}(\mathrm{A})]}\end{array}$} \\
\cline { 3 - 5 } & {$[\mathrm{n}]$} & $\mathrm{M}$ & $\mathrm{SD}$ & $\mathrm{SEM}$ \\
\hline 10 min & & & 7.39 & 1.74 \\
$\quad$ Friday* (holiday) & 18 & 70.06 & 6.32 & 0.86 \\
$\quad$ working days & 54 & 72.62 & & \\
15 min & & & 7.16 & 1.69 \\
$\quad$ Friday (holiday) & 18 & 70.31 & 6.38 & 0.87 \\
$\quad$ working days & 54 & 72.54 & & 1.63 \\
30 min & & & 6.91 & 0.87 \\
$\quad$ Friday (holiday) & 18 & 70.67 & 6.38 & \\
$\quad$ working days & 54 & 72.52 & & \\
\hline
\end{tabular}

M - mean; SD - standard deviation; SEM - standard error mean.

* Friday is the weekend holiday in Iran. 
the variables at different time-intervals were: $0.15,0.21$ and 0.29 , respectively, which reveals no significant difference between the holidays and working days. The relationship between the equivalent-continuous A-weighted sound pressure levels of working days at 3 intervals was tested by the one-way analysis of variance (ANOVA) test. According to the p-values of $0.52,0.62$ and 0.73 , no significant difference between the equivalent-continuous A-weighted sound pressure levels of working days at intervals of $10 \mathrm{~min}, 15 \mathrm{~min}$ and $30 \mathrm{~min}$ was found. The equivalent-continuous A-weighted sound pressure level on 3 occasions in the morning, noon and evening were also tested using one-way ANOVA. The p-values of 0.2, 0.18 and 0.11 revealed no significant difference between the variables. Also no significant difference between the equivalentcontinuous A-weighted sound pressure level at intervals of $10 \mathrm{~min}, 15 \mathrm{~min}$ and $30 \mathrm{~min}$ was found.

Field investigations in the district revealed that there is no industrial noise pollution source in the region. Therefore, it was concluded that vehicles would be the major source of noise pollution in District 14. According to summer time measurement results, of 91 measurement points, the average equivalent sound level of 63 stations exceeded the standard of $70 \mathrm{~dB}(\mathrm{~A})$.

Figure 3 shows the measured average equivalent-continuous A-weighted sound pressure level map of the district during the summer.

As the figure suggests, the points in the dark zones have the highest equivalent-continuous A-weighted sound pressure level; the noise pollution decreases by moving down towards lighter zones.

According to the results, the maximum equivalent-continuous A-weighted sound pressure level (84.2 dB(A)) belongs to the Qasr-e-Firoozeh Station in the Basij Highway with a residential land use. The minimum equivalentcontinuous A-weighted sound pressure level (62.3 dB(A)) was reported from Izad Panah School, with an educational land use.

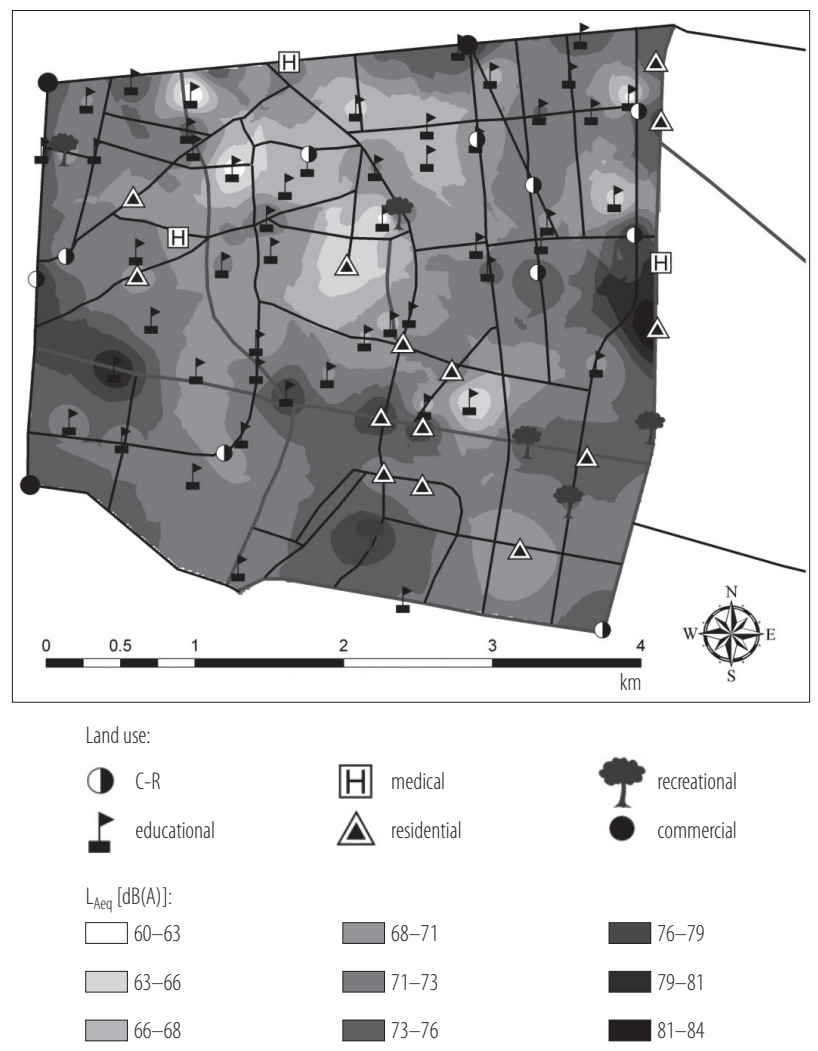

$\mathrm{C}-\mathrm{R}$ - commercial and residential land use.

$\mathrm{L}_{\text {Aeq10-min }}$ - average equivalent sound pressure level measured within a time interval of $10 \mathrm{~min}$.

Fig. 3. Spatial distribution of the $\mathrm{L}_{\text {Aeq10-min }}$ according to the various land uses in District 14

District 14 has different land uses i.e., educational, medical, residential, commercial-residential and commercial. The Iranian Department of Environment (Ir-DoE) has presented different standards in which the maximum allowable noise level of different land uses is specified (Table 3) [26].

The obtained results showed that throughout the educational land use, all the schools were exposed to an average sound pressure level higher than the standard presented by Ir-DoE.

In the medical land use, the equivalent sound level was low and close to the standard limits in 2 of the 3 hospitals $(60.5 \mathrm{~dB}(\mathrm{~A})$ and $59.9 \mathrm{~dB}(\mathrm{~A}))$ due to their green space 
Table 3. The equivalent sound pressure level $\left(\mathrm{L}_{\text {Aeq }}\right)$ in the ambient air of Iran* - daytime (7:00 a.m.-10:00 p.m.)

\begin{tabular}{lc}
\hline \multicolumn{1}{c}{ Land use } & $\begin{array}{c}\mathrm{LAeq}_{10-\text { min }} \\
{[\mathrm{dB}(\mathrm{A})]}\end{array}$ \\
\hline Residential zone & 55 \\
Commercial-residential zone & 60 \\
Commercial zone & 65 \\
Residential-industrial area & 70 \\
Industrial area & 75 \\
\hline
\end{tabular}

* Based on data from the Iranian Department of Environment (1999) [26].

$\mathrm{L}_{\text {Aeq10-min }}$ - average equivalent sound pressure level measured within a time interval of $10 \mathrm{~min}$.

and the distance from the crowded streets. The equivalent-continuous A-weighted sound pressure level exceeded the standard limit in one of the hospitals located near the main street $(70.1 \mathrm{~dB}(\mathrm{~A}))$. The problem has been solved by double glazed windows. In residential land use, most areas were exposed to a sound pressure level higher than the standard limit due to the proximity to the highways and crowded streets. The sound pressure level in commercialresidential land use, which varied between 70 to $75 \mathrm{~dB}(\mathrm{~A})$, was higher than the standard limits. This was mainly because of a crowded junction with an equivalent-continuous A-weighted sound pressure level of $81.3 \mathrm{~dB}(\mathrm{~A})$.

The one-way ANOVA test was employed to compare $\mathrm{L}_{\text {Aeq }}$ of different land uses. The results of variance homogeneity test with $p=0.25$ indicated that there is no significant difference among variances. Besides, the $p=0.001$ in the mean equality test shows that a significant difference exists among the mean values. To show this, the Duncan Test was employed. The 10 min average equivalent-continuous A-weighted sound pressure levels of different land uses are sorted as follows: commercial $(77.80 \mathrm{~dB}(\mathrm{~A}))$, residential (74.27 dB(A)), recreational (73.95 dB(A)), business-residential $(73.91 \mathrm{~dB}(\mathrm{~A}))$, educational $(70.93 \mathrm{~dB}(\mathrm{~A}))$ and medical $(63.60 \mathrm{~dB}(\mathrm{~A}))$. Figure 4 shows $10 \mathrm{~min}$ average equivalent-continuous A-weighted sound pressure levels

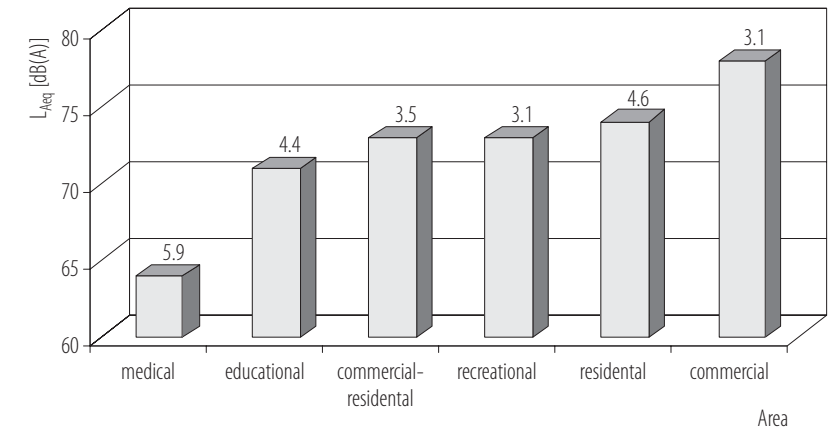

Numbers above the columns are the standard deviation values.

Fig. 4. Comparison of the average equivalentcontinuous A-weighted sound pressure levels $\left(\mathrm{L}_{\text {Aeq }}\right)$ at different land uses during the time from 7:00 a.m. till 8:00 p.m.

in different land uses during the period from 7:00 a.m. till 8:00 p.m.

Comparing recreational, residential and commercial-residential land uses, one should note that, noise pollution in the recreational land use was measured at the entrance of parks regardless of the control effects of green space. Location of the selected stations may be a reason why commercial-residential land use obtained a lower sound pressure level rather than the residential and recreational land uses. In the case of recreational and residential land uses, the stations were mostly located on the highways having high sound pressure levels.

The one-way ANOVA test was also used for comparison of the equivalent-continuous A-weighted sound pressure levels at different points of the road network. Results did not show any significant differences among the variances $(p=0.80)$. However, the means differed $(p=0)$ and the Duncan Test was employed to show the difference. Figure 5 presents a comparison of the average sound levels at different points of the road networks in District 14. High average sound pressure levels belong to: highways (77.89 $\mathrm{dB}(\mathrm{A})$ ), junctions (74.72 $\mathrm{dB}(\mathrm{A}))$, main streets $(72.10 \mathrm{~dB}(\mathrm{~A}))$, squares $(71.6 \mathrm{~dB}(\mathrm{~A}))$ and secondary streets $(67.94 \mathrm{~dB}(\mathrm{~A}))$. The $\mathrm{L}_{\text {Aeq }}$ comparison results of different types of passages revealed that the average sound pressure level is minimum 


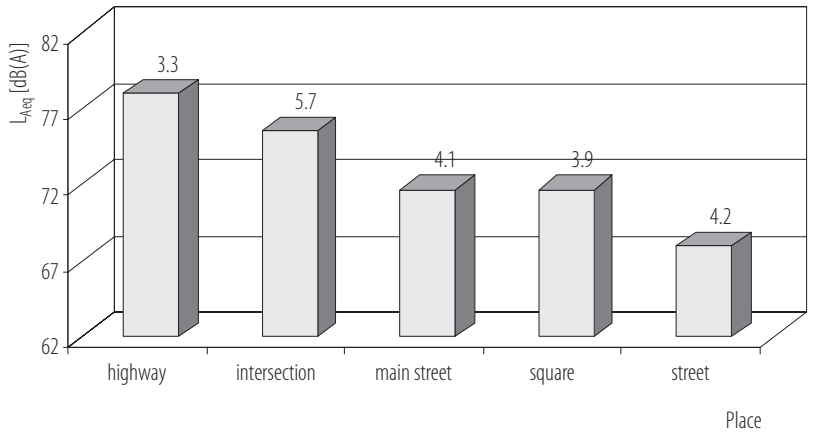

Numbers above the columns are the standard deviation values.

Fig. 5. Comparison of the average equivalentcontinuous A-weighted sound pressure levels $\left(\mathrm{L}_{\text {Aeq }}\right)$ in District 14

in secondary streets, while it reaches its peaks in highways. The junctions and main streets have almost the same sound pressure levels as highways. Therefore, there is a reasonable trend in the sound pressure level to increase from secondary streets to the main streets and highways. In other words, broadening the streets causes an increase in the speed of vehicles finally resulting in the noise pollution intensification. Higher sound pressure levels in junctions rather than in the main streets would be a result of proximity to the highways and busy main streets. In addition, vehicles that stop at the traffic lights in the junctions make high sound pressure levels; especially some old vehicles make a loud noise while pushing the brake. The honk of vehicles can also increase noise pollution.

According to the one-way ANOVA test done by Statistical Package for the Social Sciences (SPSS) 16.0, no significant difference was observed among $10 \mathrm{~min}, 15 \mathrm{~min}$ and $30 \mathrm{~min}$ average sound levels.

Golmohammadi has also acquired the same results with $10 \mathrm{~min}, 20 \mathrm{~min}, 30 \mathrm{~min}, 45 \mathrm{~min}$ and $60 \mathrm{~min}$ average sound levels in the city of Hamedan [27]. The study conducted by Safari Variani in the city of Qazvin also verifies the uniformity of the equivalent-continuous A-weighted sound pressure level during a day. Sound pressure level comparison at similar stations on different days and hours showed a difference of less than $1 \mathrm{~dB}$ approving uniform sound pressure levels caused by traffic noise as the original source, and reflection from surfaces such as street asphalt pavement or high-rise buildings as the virtual sources [28]. In the present study, no significant relationship was found between the weekdays. This is in conflict with the results reported by Golmohammadi in 2005. He stated that equivalent-continuous A-weighted sound pressure level differs on weekdays. This may be a result of traditional urban fabric and the use of conventional materials in the buildings of Hamedan, which avoids sound propagation [27].

\section{CONCLUSIONS}

The research findings suggest a time-consuming procedure by means of which it would be possible to perform noise assessment studies on a larger sample size in a shorter sampling duration. Taking into consideration rush hours during the morning and evening and reduced traffic load in the noon, it could be concluded that surfaces have significant impact on reducing the noise level fluctuations. The influence of traffic flow on noise pollution levels seems to be overshadowed by civil architecture. Changes in urban fabric have led to a perceptible change in the average daytime sound pressure level in urban areas. As such, high-rise buildings increase reflection of sound and prevent sound propagation. The use of materials such as marble, granite, glass and composite laminates (metal-like materials) in building façade increases sound reflections due to their smooth surface. With a greater number of stations in a broader area, the pilot phase should be performed simultaneously in 2 districts with old and new urban fabrics in order to obtain a more accurate comparison concerning the impact of civil architecture on the noise pollution levels in urban areas.

In the present study, there is an ample space available in the highways to be devoted for green space, which can play a role as noise pollution barrier. This should 
be done using a dense vegetation cover of broadleaf and needle leaf types of Platanus and Acacia [29]. Vegetation sound barriers with suitable technical characteristics and high surface density could be a good solution in terms of mitigating traffic noise. It is also better to have mixed walls (combination of absorptive and reflective materials) of Plexiglass sheets that can mitigate noise traffic by about $20 \mathrm{~dB}(\mathrm{~A})$. They should be designed in such a way so as to cover at least the top of the windows in the susceptible parts as acoustic shadows [30]. As far as the crowded and narrow streets are considered, route widening seems to be a good idea. Widening the streets would make it possible to devote an exclusive lane for buses and bikes. Lack of multi-story car parks in busy streets such as Piroozi and 17 Shahrivar is also noticeable.

\section{ACKNOWLEDGMENTS}

We would like to express our deepest gratitude to Ms. Hosseini, Head of GIS Section in District 14 Municipality, Mr. Kaveh Aghamiri and Dr. Amir Hossein Javid for their sincere contributions in conducting the present study. We hereby appreciate services rendered by Ravian Danesh Mohit Company in providing insightful comments and proofreading of the manuscript.

\section{REFERENCES}

1. Hamed M, Effat W. A GIS-based approach for the screening assessment of noise and vibration impacts from transit projects. J Environ Manage. 2007;84(3):305-13, http://dx.doi. org/10.1016/j.jenvman.2006.06.010.

2. De Kluijver H, Stoter J. Noise mapping and GIS: Optimising quality and efficiency of noise effect studies. Comput Environ Urban Syst. 2003;27(1):85-102, http://dx.doi.org/10.1016/ S0198-9715(01)00038-2.

3. Clark C, Head J, Stansfeld SA. Longitudinal effects of aircraft noise exposure on children's health and cognition: A six-year follow-up of the UK RANCH cohort. J Environ Psychol. 2013;35:1-9, http://dx.doi.org/10.1016/j.jenvp. 2013.03.002.
4. Hohmann C, Grabenhenrich L, de Kluizenaar Y, Tischer C, Heinrich J, Chen CM, et al. Health effects of chronic noise exposure in pregnancy and childhood: A systematic review initiated by ENRIECO. Int J Hyg Environ Health. 2013;216(3):217-29, http://dx.doi.org/10.1016/j.ijh eh.2012.06.001.

5. Golmohammadi R, Monazzam MR, Nourollahi M, Nezafat A. Noise characteristics of pumps at Tehran's oil refinery and control module design. Pakistan J Sci Ind Res. 2009;52(3):167-72.

6. Naish DA, Tan ACC, Nur Demirbilek F. Estimating health related costs and savings from balcony acoustic design for road traffic noise. Appl Acoust. 2012;73(5):497-507, http:// dx.doi.org/10.1016/j.apacoust.2011.12.005.

7. Chao PC, Juang YJ, Chen CJ, Dai YT, Yeh CY, Hu CY. Combined effects of noise, vibration, and low temperature on the physiological parameters of labor employees. Kaohsiung J Med Sci. 2013;29(10):560-7, http://dx.doi. org/10.1016/j.kjms.2013.03.004.

8. Reed SE, Boggs JL, Mann JP. A GIS tool for modeling anthropogenic noise propagation in natural ecosystems. Environ Model Softw. 2012;37:1-5, http://dx.doi.org/10.1016/ j.envsoft.2012.04.012.

9. Ko JH, Chang S, Lee BC. Noise impact assessment by utilizing noise map and GIS: A case study in the city of Chungju, Republic of Korea. Appl Acoust. 2011;72(8):544-50, http:// dx.doi.org/10.1016/j.apacoust.2010.09.002

10. Babisch W, Pershagen G, Selander J, Houthuijs D, Breugelmans O, Cadum E, et al. Noise annoyance - A modifier of the association between noise level and cardiovascular health? Sci Total Environ. 2013;452-453:50-7, http://dx.doi. org/10.1016/j.scitotenv.2013.02.034.

11. Dintrans A, Préndez M. A method of assessing measures to reduce road traffic noise: A case study in Santiago, Chile. Appl Acoust. 2013;74(12):1486-91, http://dx.doi.org/ 10.1016/j.apacoust.2013.06.012.

12. Monazzam MR, Naderzadeh M, Nassiri P, Fard SMB. Performance of environmental T-shape noise barriers 
covered with primitive root diffusers. Radiat Prot Dosim. 2010;145(4):421-5.

13. Fyhri A, Aasvang GM. Noise, sleep and poor health: Modeling the relationship between road traffic noise and cardiovascular problems. Sci Total Environ. 2010;408(21):4935-42, http://dx.doi.org/10.1016/j.scitotenv.2010.06.057.

14. Kim M, Chang SI, Seong JC, Holt JB, Park TH, Ko JH, et al. Road traffic noise: Annoyance, sleep disturbance, and public health implications. Am J Prev Med. 2012;43(4):353-60, http://dx.doi.org/10.1016/j.amepre.2012.06.014.

15. Abbaspour M, Karimi E, Nassiri P, Monazzam MR, Taghavi L. Hierarchal assessment of noise pollution in urban areas - A case study. Transport Res D. 2015;34:95-103.

16. Muzet A. Environmental noise, sleep and health. Sleep Med Rev. 2007;11(2):135-42, http://dx.doi.org/10.1016/j.sm rv.2006.09.001.

17. Xie H, Kang J, Mills GH. Behavior observation of major noise sources in critical care wards. J Crit Care. 2013;28(6):1109. e5-18, http://dx.doi.org/10.1016/j.jcrc.2013.06.006.

18. Li B, Tao S, Dawson RW, Cao J, Lam K. A GIS based road traffic noise prediction model. Appl Acoust. 2002;63(6): 679-91, http://dx.doi.org/10.1016/S0003-682X(01)00066-4.

19. Pamanikabud P, Tansatcha M. Geoinformatic prediction of motorway noise on buildings in 3D GIS. Transport Res D-Tr E. 2009;14(5):367-72, http://dx.doi.org/10.1016/ j.trd.2009.04.001.

20. Cho DS, Kim JH, Manvell D. Noise mapping using measured noise and GPS data. Appl Acoust. 2007;68(9): 1054-61, http://dx.doi.org/10.1016/j.apacoust.2006.04.015.

21. Kang-Ting T, Min-Der L, Yen-Hua C. Noise mapping in urban environments: A Taiwan study. Appl Acoust. 2009;70(7):964-72, http://dx.doi.org/10.1016/j.apacoust.2008.11.001.

22. Mehdi M, Kim M, Seong J, Arsalan M. Spatio-temporal patterns of road traffic noise pollution in Karachi, Pakistan.
Environ Int. 2011;37(1):97-104, http://dx.doi.org/10.1016/ j.envint.2010.08.003.

23. Tang UW, Wang ZS. Influences of urban forms on trafficinduced noise and air pollution: Results from a modeling system. Environ Model Softw. 2007;22(12):1750-64, http:// dx.doi.org/10.1016/j.envsoft.2007.02.003.

24. Fung YW, Lee WL. Identifying a common parameter for assessing the impact of traffic-induced noise and air pollution on residential premises in Hong Kong. Habitat Int. 2011;35(2):231-7, http://dx.doi.org/10.1016/j.habitatint. 2010.09.007.

25. Environment Protection Authority. Environmental criteria for road traffic noise. Chatswood: Environment Protection Authority; 1999.

26. Iranian Department of Environment. [The equivalent sound pressure level in ambient air of Iran, 1999] [cited 2013 Oct 12]. Available from: http://www.DOE.ir. Persian.

27. Golmohammadi R. [Development of traffic noise pollution index for main thoroughfares in cities] [Ph.D. thesis]. Tehran, Iran: Islamic Azad University, Science and Research Branch; 2005. p. 232-6. Persian.

28. Safari Variani A, Nikpay A, Ghalenoie M, Emamjomeh MM. [Comparison of equivalent sound level and traffic noise pollution index values in the counties of Qazvin Province in 2010]. Qazvin J Med Sci. 2012;16(6):70-4. Persian.

29. Khouban L, Nassiri P, Abbaspour M. Site selection and design of noise barriers in Hemmat Highway, Destrict 22 of Tehran Metropolitan City. Proceedings of the 2nd Conference on Air Pollution and its Impact on Health, Tehran, Iran; 2006. Tehran: Clean Environment Research Institute; 2006. p. 1-19.

30. Fallah F, Parvaresh B. Noise barrier technologies in highway noise control. Proceedings of the 4th Conference on Environmental Engineering, Tehran, Iran; 2010.

This work is available in Open Access model and licensed under a Creative Commons Attribution-NonCommercial 3.0 Poland License - http://creativecommons.org/ licenses/by-nc/3.0/pl/deed.en. 